\title{
Brazilian Pepper's Impact on Barrier Island Biodiversity
}

Grayson McCormick

University of South Florida

Advisors:

Arcadii Grinshpan, Mathematics and Statistics

Daniel Larremore, Environmental Specialist for Honeymoon Island State Park

Problem Suggested By: Daniel Larremore

Follow this and additional works at: https://digitalcommons.usf.edu/ujmm

Part of the Mathematics Commons

UJMM is an open access journal, free to authors and readers, and relies on your support:

Donate Now

\section{Recommended Citation}

McCormick, Grayson (2010) "Brazilian Pepper's Impact on Barrier Island Biodiversity," Undergraduate Journal of Mathematical Modeling: One + Two: Vol. 3: Iss. 1, Article 2.

DOI: http://dx.doi.org/10.5038/2326-3652.3.1.14

Available at: https://digitalcommons.usf.edu/ujmm/vol3/iss1/14 


\title{
Brazilian Pepper's Impact on Barrier Island Biodiversity
}

\begin{abstract}
The Brazilian pepper is an invasive plant responsible for destruction of habitats of species native to Florida. We attempted to measure the impact of the Brazilian pepper on native plants by studying how it affects the biodiversity of Honeymoon Island, one of Florida's barrier islands. For this purpose we determined the population sizes of the Brazilian pepper along with five other species of plants on two quadrats of land laid out in Honeymoon Island State Park. Both Simpson's Index of Diversity and Shannon-Wiener Index were used to estimate the biodiversity and assess the impact of the Brazilian pepper on the island's habitats.
\end{abstract}

Keywords

Brazilian Pepper, Simpson's Index of Diversity, Shannon Wiener Index, Unified Theory

Creative Commons License

(c) (i) (8)

This work is licensed under a Creative Commons Attribution-Noncommercial-Share Alike 4.0 License.

\section{Erratum}

This article was previously called Article 14. 


\section{TABLE OF CONTENTS}

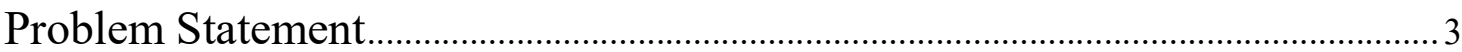

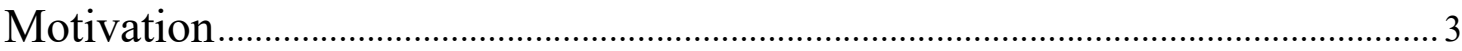

Mathematical Description and Solution Approach ................................................ 4

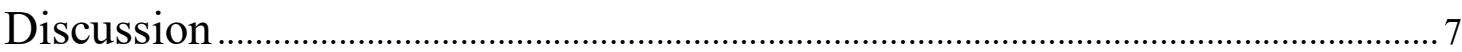

Conclusion and Recommendations..................................................................

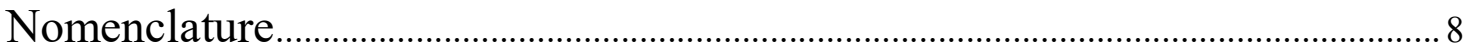

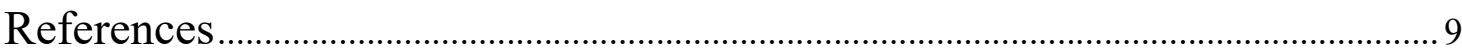




\section{PROBLEM STATEMENT}

The goal of this project is to describe the impact of the Brazilian pepper on the diversity of native plants of Honeymoon Island.

\section{MOTIVATION}

Honeymoon Island is a barrier island west of Dunedin, Florida that is home to many coastal plant species. The three types of habitats found on the island are mangrove swamps, upland scrubs, and beach/dune habitat plus transitional areas in between. Due to the limited amount of space, the shape and the distribution of island's habitats are constantly changing making it difficult to accurately determine their boundaries. Figure 1 shows approximate locations of these habitats as well as large transitional areas between them.

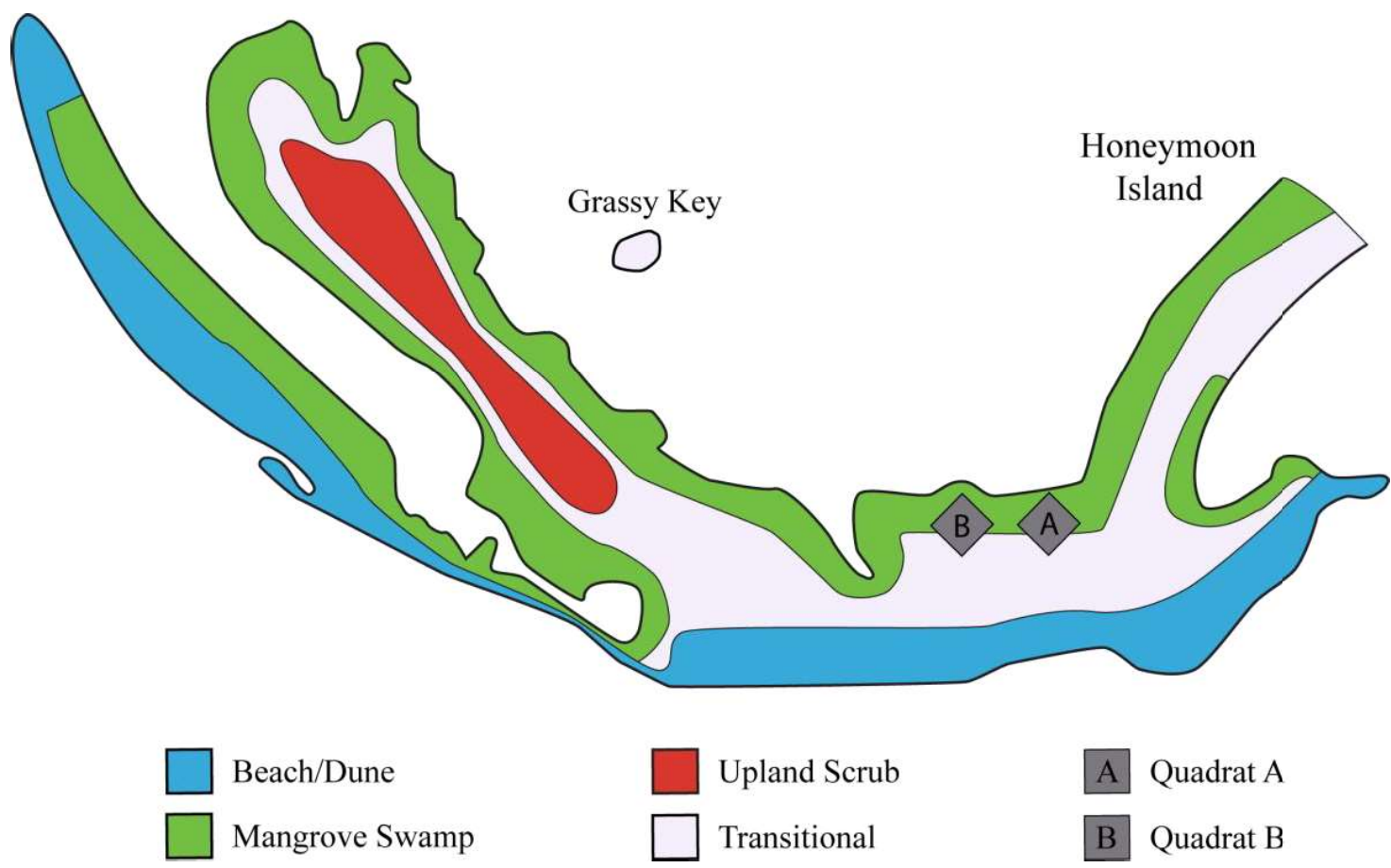

Figure 1: A map of Honeymoon Island showing the locations of quadrats $A$ and $B$ along with approximate boundaries of island's habitats. 
Island's diverse ecosystem is an ideal place to study the impact of invasive exotic plants.

We chose the Brazilian pepper because it is on top of the list of problem species in Florida (Ferriter and Clarke). This Amazon native can grow up to 40 feet high and possesses a thick layer of branches (Morton). Honeymoon Island contains a large population of the Brazilian pepper and this project seeks to show the decline of overall vegetation biodiversity in the areas it infested.
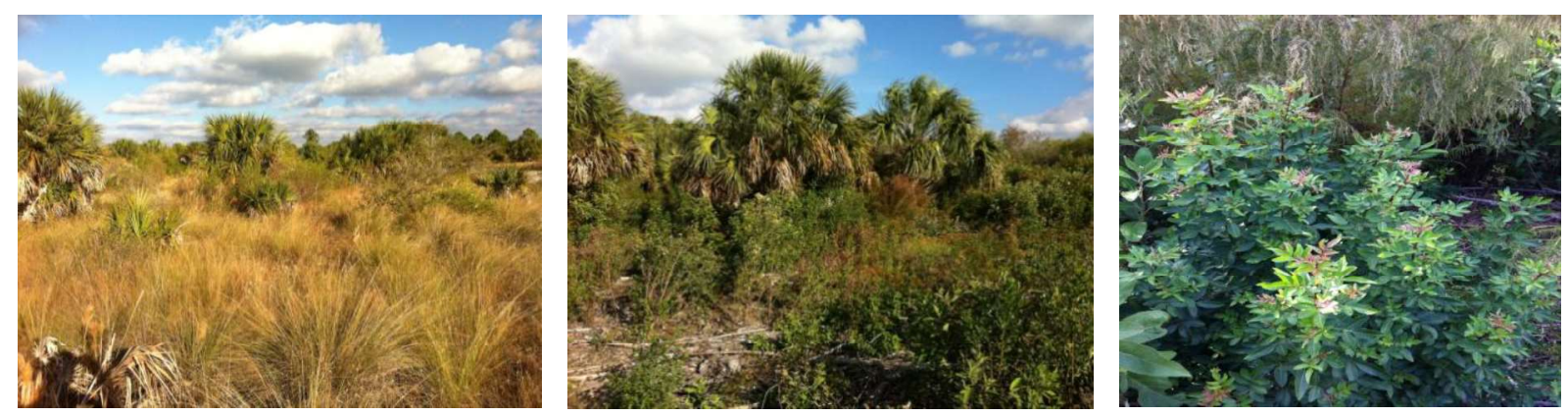

Figure 2: Photos of quadrats A (left) and B (center), and Brazilian Pepper plant from quadrat B (right).

Our sample consisted of two $35^{\prime} \times 35^{\prime}$ quadrats laid out in the Honeymoon Island State Park (see Fig. 1 and 2). Locations of both quadrats have similar topographic characteristics but differ in the Brazilian pepper's population sizes. Quadrat A is very sparsely populated while Quadrat B contains many individuals.

\section{MATHEMATICAL DESCRIPTION AND SOLUTION APPROACH}

To estimate Brazilian Pepper's impact on biodiversity of Honeymoon Island we calculated Simpson's Diversity Index $(D)$ and Shannon-Wiener Index $\left(H^{\prime}\right)$. Given $N$ species with $n_{1}, n_{2}, \ldots, n_{k}$ individuals of each species these indices are given by 


$$
D=1-\sum_{i=1}^{k} p_{i}^{2} \quad \text { and } \quad H^{\prime}=-\sum_{i=1}^{k}\left(p_{i} \ln p_{i}\right)
$$

where $p_{i}=n_{i} / N$. See (Gore and Paranjpe) for description of basic properties of both of these indices.

Tables 1 and 2 contain the data collected from quadrats A and B as well as our calculations.

\begin{tabular}{|lccccc|}
\multicolumn{1}{c}{ Plant } & \# Individuals & $\boldsymbol{p}_{\boldsymbol{i}}$ & $\boldsymbol{p}_{\boldsymbol{i}}^{2}$ & $\boldsymbol{\operatorname { l n }} \boldsymbol{p}_{\boldsymbol{i}}$ & $\boldsymbol{p}_{\boldsymbol{i}} \ln \boldsymbol{p}_{\boldsymbol{i}}$ \\
\hline Privett & 31 & 0.5849 & 0.3421 & -0.5363 & -0.3137 \\
\hline Slash Pine & 1 & 0.0189 & 0.0004 & -3.9686 & -0.0750 \\
\hline Cabbage Palm & 10 & 0.1887 & 0.0356 & -1.6676 & -0.3147 \\
\hline Saltbush & 8 & 0.1509 & 0.0228 & -1.8911 & -0.2854 \\
\hline Brazilian Pepper & 1 & 0.0189 & 0.0004 & -3.9686 & -0.0750 \\
\hline Scrub Oak & 2 & 0.0377 & 0.0014 & -3.2781 & -0.1236 \\
\hline Total & 53 & \multicolumn{5}{c}{0.4027} & -1.1874 \\
\hline \multicolumn{2}{r}{ Simpson's Index $(\boldsymbol{D}): 0.5973$} \\
\hline
\end{tabular}

Table 1: Biodiversity indices for data from quadrat A.

\begin{tabular}{|lccccc|}
\hline \multicolumn{1}{c}{ Plant } & \# Individuals & $\boldsymbol{p}_{\boldsymbol{i}}$ & $\boldsymbol{p}_{\boldsymbol{i}}^{2}$ & $\boldsymbol{\operatorname { l n }} \boldsymbol{p}_{\boldsymbol{i}}$ & $\boldsymbol{p}_{\boldsymbol{i}} \ln \boldsymbol{p}_{\boldsymbol{i}}$ \\
\hline Privett & 5 & 0.0685 & 0.0047 & -2.6809 & -0.1836 \\
\hline Slash Pine & 0 & 0.0000 & 0.0000 & - & - \\
\hline Cabbage Palm & 2 & 0.0274 & 0.0008 & -3.5972 & -0.0986 \\
\hline Saltbush & 20 & 0.2740 & 0.0750 & -1.2946 & -0.3547 \\
\hline Brazilian Pepper & 46 & 0.6301 & 0.3970 & -0.4609 & -0.2904 \\
\hline Scrub Oak & 0 & 0.0000 & 0.0000 & - & - \\
\hline Total & 73 & \multicolumn{5}{c}{0.4775} & -0.9273 \\
\hline \multicolumn{5}{r}{ Simpson's Index $(\boldsymbol{D}): 0.5225$} & \multicolumn{3}{c}{ Shannon-Weiner Index $\left(H^{\prime}\right): 0.9279$} \\
\hline
\end{tabular}

Table 2: Biodiversity indices for data from quadrat B. 
Besides estimating biodiversity, two quadrats can be compared by estimating the distribution of relative species abundance. One way to obtain such distribution is to use Hubbell's Unified neutral theory of biodiversity (Hubbell). According to (Volkov, Banavar and Hubbell) the average number of species containing $n$ individuals is given by

$$
\left\langle\varphi_{n}\right\rangle=\theta \frac{J !}{n !(J-n) !} \frac{\Gamma(\gamma)}{\Gamma(\mathrm{J}+\gamma)} \int_{0}^{\gamma} \frac{\Gamma(\mathrm{n}+\mathrm{y})}{\Gamma(1+\mathrm{y})} \frac{\Gamma(\mathrm{J}-\mathrm{n}+\gamma-\mathrm{y})}{\Gamma(\gamma-\mathrm{y})} \exp \left(-\frac{-y \theta}{\gamma}\right) d y
$$

where $\Gamma(x)$ is the gamma function, $J$ is the size of local community, $\gamma=m(J-1) /(1-m), m$ is the immigration rate, and $\theta$ is the biodiversity parameter. Although the immigration rate and biodiversity parameter are unknown for either quadrats, we assume that $\theta=31.8$ and $m=0.05$ to demonstrate one possible distribution (see Fig. 3).

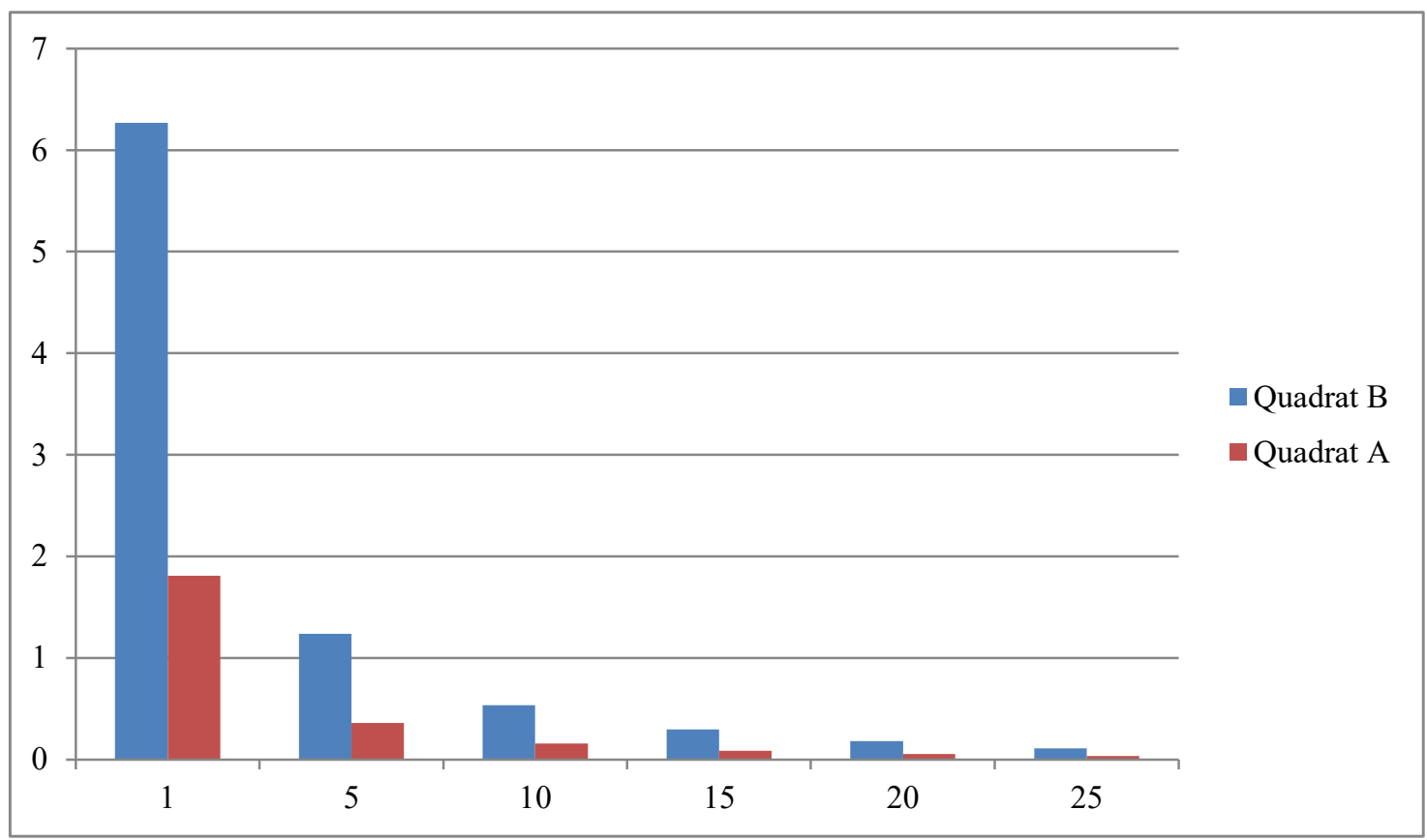

Figure 3: A possible distribution of average numbers of species with given number of individuals. 


\section{DISCUSSION}

As expected, our calculations have shown that quadrat B has less biodiversity than quadrat A according to both indices. The values of Simpson's Index of Diversity $(D)$ and Shannon-Weiner Index $\left(H^{\prime}\right)$ for quadrat B were 0.5225 and 0.9279 respectively. Values of both indices were significantly higher for quadrat A, where we obtained $D=0.5973$ and $H^{\prime}=$ 1.1874. This means that not only quadrat $\mathrm{A}$ is richer in species but also that its species are more evenly distributed. It is likely that the Shannon-Weiner Index provides a better estimate of the biodiversity because the difference of $H^{\prime}$ indices of both quadrants is greater than the difference of $D$ indices. Once the biodiversity parameter and the immigration rate are determined, it would be possible to compare the above biodiversity estimates with distribution of average number of species with given number of individuals estimated through Hubbell's Unified Theory.

\section{CONCLUSION AND RECOMMENDATIONS}

We have successfully used Simpson's Diversity Index and Shannon-Wiener Index to quantitatively describe biodiversity of two quadrats in Honeymoon Island State Park. Both indices indicated that quadrat B has less biodiversity than quadrat $\mathrm{A}$, which is consistent with our intuition. We believe that our findings give an accurate estimate of true biodiversity of Honeymoon Island and indicative of other places with large populations of the Brazilian pepper.

Naturally, our study has some limitations. For instance, we have only investigated how the Brazilian pepper affects plant biodiversity. However, changes in plant populations affect animal life and hence the impact of the Brazilian pepper reaches beyond plants (see (Morton) for more information on this topic). 
We believe it would be useful to do another longer-term study that includes more quadrats of larger area. Such study could consider at least twice as many species of plants and give special attention to the species commonly found in each type of habitat. Including at least two quadrats for each type of habitat (total of six in the case of Honeymoon Island) would help to get a less biased estimate of true biodiversity.

\section{NOMENCLATURE}

\begin{tabular}{|c|c|}
\hline Symbol & Description \\
\hline$N$ & Total number of individuals of all species sampled \\
\hline $\boldsymbol{n}_{\boldsymbol{i}}$ & Number of individuals of $i$ th species sampled \\
\hline $\boldsymbol{p}_{\boldsymbol{i}}$ & Probability that an individual belongs to species $i$ \\
\hline$D=1-\sum_{i=1}^{k} p_{i}^{2}$ & Simpson's Index of Diversity \\
\hline$H^{\prime}=-\sum_{i=1}^{k}\left(p_{i} \ln p_{i}\right)$ & Shannon-Wiener Index \\
\hline$\varphi_{n}$ & $\begin{array}{l}\text { average number of species containing } n \\
\text { individuals }\end{array}$ \\
\hline $\boldsymbol{\theta}$ & the biodiversity parameter \\
\hline $\boldsymbol{m}$ & immigration rate \\
\hline
\end{tabular}




\section{REFERENCES}

Ferriter, Amy and Dan Clarke. "Brazilian Pepper Management Plan." July 1997. Florida Exotic Pest Plant Council. 2010. December $2010<$ http://www.fleppc.org/Manage_Plans/schinus.pdf $>$.

Gore, Anil and Sharayu Paranjpe. A Course in Mathematical and Statistical Ecology. Kluwer Academic Publishers, 2001.

Hubbell, Stephen P. The Unified Neutral Theory of Biodiversity and Biogeography. Princeton University Press, 2001.

Morton, Julia F. "Brazilian Pepper - its Impact on People, Animals and the Environment." Economic Botany (1978): 353-359.

Volkov, Igor, et al. "Neutral theory and relative species abundance in ecology." Nature (2003): 10351037. 